\title{
Root and canal symmetry in the mandibular anterior teeth of patients attending a dental clinic: CBCT study
}

\section{Guven KAYAOGLU(a) Ilkay PEKER(b) \\ Mustafa GUMUSOK(b) \\ Cigdem SARIKIR(b) \\ Aylin KAYADUGUN ${ }^{(b)}$ \\ Ozlem UCOK(b)}

(a) Gazi University, Faculty of Dentistry, Department of Endodontics, Emek, Ankara, Turkey.

(b)Gazi University, Faculty of Dentistry, Department of Dentomaxillofacial Radiology, Emek, Ankara, Turkey.

Declaration of Interests: The authors certify that they have no commercial or associative interest that represents a conflict of interest in connection with the manuscript.

Corresponding Author:

Guven Kayaoglu

E-mail: guvenkayaoglu@gmail.com

DOI: 10.1590/1807-3107BOR-2015.vol29.0090

Submitted: Feb 07, 2015

Accepted for publication: Apr 06, 2015

Last revision: Jun 09, 2015

\begin{abstract}
The aims of this study were to evaluate the number of roots/root canals in the mandibular anterior teeth of a Turkish population, to assess the relationship between gender or age and the frequency of two canals in a single root, and to determine the symmetry in root/root canal numbers between contralateral sides among patients. Cone-beam computed tomography images $(n=1128 ; 6253$ teeth) taken at the Department of Dentomaxillofacial Radiology of the Faculty of Dentistry of Gazi University were examined by three observers and a supervisor, all of whom were blinded to patient gender and age. Axial, sagittal, and cross-sectional slices with a thickness of $1 \mathrm{~mm}$ were used. Numbers of roots and canals for each type of tooth were recorded. Most teeth had a single root and single root canal. Roots with two canals were more frequent in the incisors $(14.9 \%, 17.2 \%$, and $6.1 \%$ of the central incisors, lateral incisors, and canines, respectively). Teeth with two roots were more frequent in the canines $(3.1 \%$ vs. $0 \%$ or $0.1 \%)$. Females more often had canines with double root canals $(\mathrm{p}<0.001)$. When at least one tooth had two root canals, bilateral symmetry between contralateral teeth was found in $45.0 \%, 29.0 \%$, and $28.0 \%$ of cases for central incisors, lateral incisors, and canines, respectively. Patients older than 56 years had fewer teeth with double root canals $(\mathrm{p} \leq 0.001)$. A small proportion of the mandibular anterior teeth had two roots or root canals. Double root canals were mostly unilateral. Age and gender were associated with the number of root canals.
\end{abstract}

Keywords: Anatomy; Endodontics; Prevalence; Radiography.

\section{Introduction}

Thorough knowledge of tooth anatomy, root canal morphology, and morphological variations is necessary for successful endodontic treatment and may be critical for other dental procedures, such as periodontal treatment, periapical surgery, tooth extraction, etc. In addition to their medical relevance, anatomical variations are important for anthropological science and forensic issues. Normally, the root canal systems of mandibular central and lateral incisors are similar, with a coronally oval shape (wider bucco-lingually than mesio-distally) that gradually becomes narrower bucco-lingually at mid-root. ${ }^{1}$ Mandibular incisors most often have a single root; however, a dentinal bridge may sometimes divide the root into two canals, and further variations may be seen. ${ }^{1,2}$ Mandibular canines, 
similar to mandibular incisors, have a root wider bucco-lingually than mesio-distally and contain a root canal consistent with this shape. These teeth seldom have two or more roots or canals. ${ }^{1,2}$

Although root and canal morphologies of mandibular incisors have been investigated in diverse populations, ${ }^{3,4}$ the relationship between demographic factors and morphological variations has been less extensively studied. Because dentin deposition by odontoblasts is a continuous process after eruption (secondary dentin formation), age-related calcification differences may be seen in the root canals of teeth from patients of different ages, with total obliteration of the canal space in older patients. Gender was not significantly related to variations in tooth or root canal morphology in the mandibular anterior teeth. ${ }^{4}$ Root canal morphology has generally been investigated in extracted teeth by cross-sectioning, clearing, operating or scanning electron microscopy, or radiographic examination, $5,6,7,8,9$ such as periapical radiography, cone-beam computed tomography (CBCT), and micro-computed tomography. ${ }^{4,8,10,11}$ Radiographic techniques allow for screening a large number of teeth for morphological evaluation.

The anatomic symmetry of roots between the right and left sides in the same patient has been little studied but is highly clinically relevant when treating two opposite teeth in the same patient. ${ }^{12}$ Although symmetry of the root and root canal morphologies of premolar and molar teeth have been investigated by $\mathrm{CBCT},{ }^{13,14}$ symmetry of the mandibular incisors and canines has only been investigated recently and in a limited number of studies. ${ }^{11,15}$ Therefore, the aims of this study were to investigate the relationship between demographic variables (age and gender) and the number of roots and root canals in the mandibular anterior teeth of a Turkish population, and to determine the symmetry in the numbers of roots and root canals between contralateral sides in the same patient.

\section{Methodology}

This retrospective study was approved by the Ethical Review Board of the Faculty of Dentistry of Ankara University (No. 36290600/33). Informed consent was routinely obtained from all patients before clinical and radiographic examinations. Initial material consisted of demographic data (gender and age) and CBCT images from 2828 patients who visited the Department of Dentomaxillofacial Radiology of the Faculty of Dentistry of Gazi University between January 2012 and January 2014. Main reasons for CBCT requests were implant planning, jaw lesions, the relationship of the mandibular canal to the roots of third molars, and localization of impacted teeth. CBCT images were included if they met the following criteria: presence of at least one mandibular anterior tooth, which had no periapical lesions, root canal fillings, post restorations, coronal restorations, or fixed crown restorations, and the CBCT image was of good quality and free of artifacts. After excluding images that did not meet the inclusion criteria, 1128 CBCT images were included in the study.

CBCT images were obtained by using a Promax 3D unit (Planmeca, Helsinki, Finland) operated at $84 \mathrm{kVp}$ and 9-14 $\mathrm{mA}$ with a voxel size of $0.16 \mathrm{~mm}$, exposure time of 6 seconds, and field of view of 8 centimeters. Images were examined by three oral radiology residents with at least 2 years of CBCT experience (MG, AK, and CS; $\mathrm{n}=376$ images each) and were analyzed with a built-in software package (Planmeca, Romexis viewer 2.7.0) on a 24-inch Nvidia Quadro FX 380 screen with $1280 \times 1024$ resolution in a quiet room with subdued ambient lighting. An experienced oral radiologist (IP) reviewed the examination records. Observers were allowed to manipulate the contrast and brightness features and to use the zoom tool of the software for optimal visualization. Axial, sagittal, and cross-sectional slices (thickness: $1 \mathrm{~mm}$ ) of CBCT images were used. All observers were blinded to the gender and age of the patients.

Mandibular anterior teeth were evaluated for the number and symmetry of roots and root canals. All root canal configurations, except type I (single canal) and type VIII (three canals), were registered as two root canals. ${ }^{16}$ Teeth with two roots were further examined for the length of the roots and location of the interradicular bifurcation. The root length was considered as the distance between the cemento-enamel junction and the root apex; the coronal, middle and apical third distinction of the bifurcation point was performed according to the determined length. ${ }^{16}$ 
Patient age was stratified into three categories: 10-35 years, $36-55$ years, and 56+ years. Data were statistically analyzed by using crosstabs, descriptive statistics, and the chi-square, Fisher's exact, $t$-, and z-tests. A p-value of 0.05 was considered as the level of statistical significance.

\section{Results}

In total, 6253 mandibular anterior teeth (1983 central incisors, 2077 lateral incisors, and 2193 canines) from 1128 individuals (628 females, $55.7 \%$ and 500 males, $44.3 \%$ ) aged between 10 and 85 years (mean \pm standard deviation: $41.8 \pm 15.5$ years) were examined. All central incisors were single-rooted $(\mathrm{n}=1983,100 \%)$. Most lateral incisors were single-rooted $(\mathrm{n}=2075$, $99.9 \%$ ); only $0.1 \%(n=2$, Figure 1$)$ had two roots. The frequency of mandibular canines with one root was $96.9 \%(n=2124)$ and with two roots was $3.1 \%$ $(\mathrm{n}=69)$. A statistically significant difference was found between the number of roots ( 1 vs. 2 roots) for each tooth type $(p<0.001$ by chi-square and Fisher's exact tests, Table 1).

Most mandibular anterior teeth had one canal. Double root canals in single roots were observed
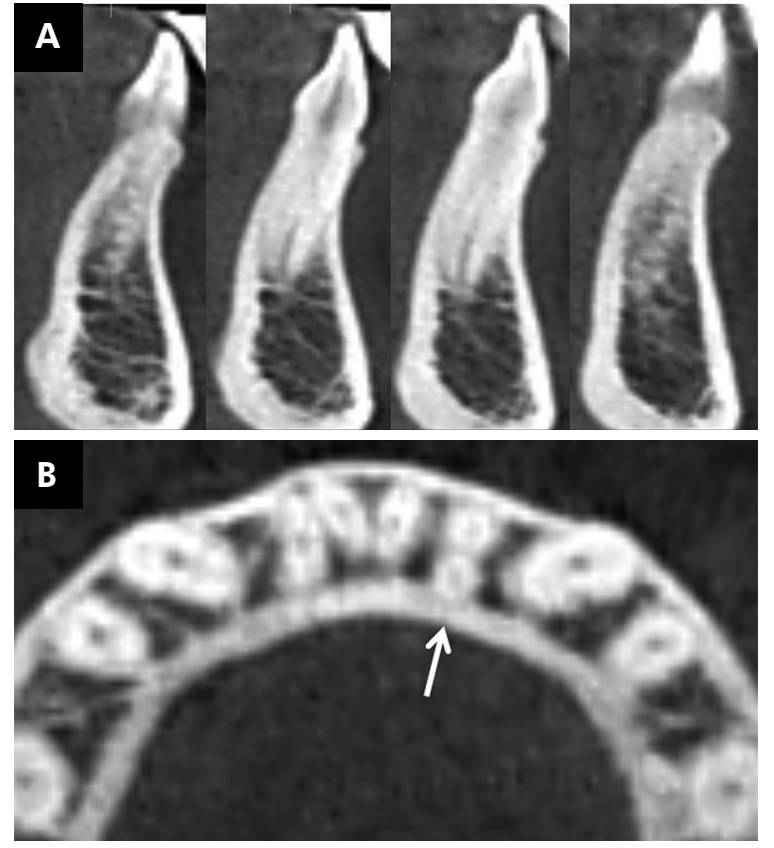

Figure 1. Sagittal ( $A$; $1 \mathrm{~mm}$ sequential sections) and axial sections (B) showing a lateral incisor with two roots (arrow). mostly in the lateral incisors ( $\mathrm{n}=357,17.2 \%$; Figure 2), followed by the central incisors ( $n=296,14.9 \%$ ) and canines ( $n=134,6.1 \%)$. Three or more canals were not observed. A statistically significant difference was found between the number of root canals ( 1 vs. 2 root canals) for each tooth type ( $p<0.001$ by chi-square and Fisher's exact tests, Table 1).

No significant difference was found for the percentages of two roots or two root canals between males and females ( $p>0.05$ by z-test, Table 2 ). The only significant difference was for the percentage of canines with two root canals ( $p<0.001)$, for which females had a higher percentage than males.

In teeth with two roots, the roots were always located in a bucco-lingual direction, with the buccal root being slightly longer than the lingual root. In canines from males and females, mean lengths of the buccal root were $13.58 \pm 1.55 \mathrm{~mm}$ and $12.29 \pm 1.91 \mathrm{~mm}$, and mean lengths of the lingual roots were $12.21 \pm 1.77 \mathrm{~mm}$ and $11.88 \pm 1.13 \mathrm{~mm}$, respectively ( $\mathrm{p}>0.05$ by $\mathrm{t}$-test between genders). A significant difference in the lengths of the buccal and lingual roots was found in males ( $p=0.008$ by $t$-test $)$, but not in females $(\mathrm{p}=0.280)$. The bifurcation point in two-rooted canines was mostly located at the middle third of the root $(81.2 \%, \mathrm{n}=56)$, followed by the apical third $(10.1 \%, \mathrm{n}=7)$ and the coronal third $(8.7 \%$, $\mathrm{n}=6$ ). In two-rooted lateral incisors, the bifurcation was located in the middle or apical third of the root $(50 \%, \mathrm{n}=1$ each).
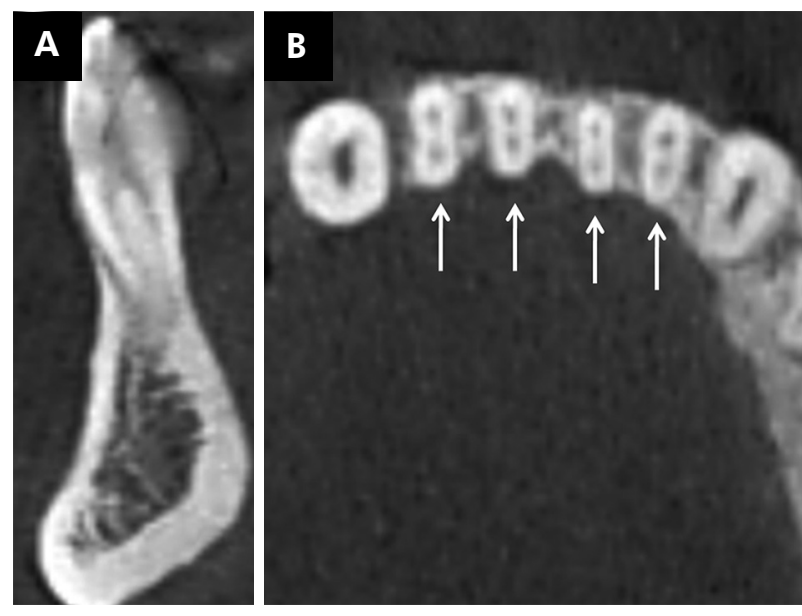

Figure 2. Sagittal (A) and axial sections (B) showing central and lateral incisors with two canals in single root (arrows). 
Root and canal symmetry in the mandibular anterior teeth of patients attending a dental clinic: CBCT study

Table 1. Distribution of the numbers of roots and root canals in the mandibular anterior teeth, and statistical results.

\begin{tabular}{|c|c|c|c|c|c|c|}
\hline \multirow{2}{*}{$\begin{array}{l}\text { Teeth } \\
\text { Central incisors }\end{array}$} & \multicolumn{2}{|c|}{ No. of roots or root canals } & \multirow{2}{*}{$\frac{N(\%)}{1983(100 \%)}$} & \multirow{2}{*}{$\begin{array}{c}\text { Pearson Chi-square } \\
\dagger\end{array}$} & \multirow{2}{*}{$\frac{\text { Df }}{\dagger}$} & \multirow{2}{*}{$\frac{\text { P-value }}{+}$} \\
\hline & No. roots & One & & & & \\
\hline & & Two & 0 & & & \\
\hline & No. root canals & One & $1687(85.1 \%)$ & 1486.648 & 4 & $0.000^{*}$ \\
\hline & & Two & 296 (14.9\%) & & & \\
\hline \multirow[t]{4}{*}{ Lateral incisors } & No. roots & One & 2075 (99.9\%) & 484.212 & 2 & $0.000^{*}$ \\
\hline & & Two & $2(0.1 \%)$ & & & \\
\hline & No. root canals & One & $1720(82.8 \%)$ & 929.568 & 4 & $0.000^{*}$ \\
\hline & & Two & 357 (17.2\%) & & & \\
\hline \multirow[t]{4}{*}{ Canines } & No. roots & One & $2124(96.9 \%)$ & 73.035 & 4 & $0.000^{*}$ \\
\hline & & Two & $69(3.1 \%)$ & & & \\
\hline & No. root canals & One & 2059 (93.9\%) & 171.226 & 4 & $0.000^{*}$ \\
\hline & & Two & $134(6.1 \%)$ & & & \\
\hline
\end{tabular}

Df: Degree of freedom.

†Statistical analysis not performed.

*Difference is statistically significant $(p<0.001)$.

Table 2. Distribution of the mandibular anterior teeth with two roots or two root canals by gender, and statistical results. Values in parentheses signify the percentage within all teeth for the specified tooth type and gender.

\begin{tabular}{|c|c|c|c|c|c|}
\hline \multirow{2}{*}{$\begin{array}{l}\text { Teeth } \\
\text { Central incisors }\end{array}$} & \multicolumn{2}{|c|}{ Variable } & \multirow{2}{*}{$\frac{N(\%)}{0}$} & \multirow{2}{*}{$\frac{\text { Z-value }}{\dagger}$} & \multirow{2}{*}{$\frac{\text { P-value }}{\dagger}$} \\
\hline & Two roots & Male & & & \\
\hline & & Female & 0 & & \\
\hline & Two root canals & Male & 138 (16.2\%) & 0.7 & 0.497 \\
\hline & & Female & 158 (13.4\%) & & \\
\hline \multirow[t]{4}{*}{ Lateral incisors } & Two roots & Male & 0 & $\dagger$ & $\dagger$ \\
\hline & & Female & $2(0.2 \%)$ & & \\
\hline & Two root canals & Male & $170(18.8 \%)$ & 0.7 & 0.485 \\
\hline & & Female & 187 (16\%) & & \\
\hline \multirow[t]{4}{*}{ Canines } & Two roots & Male & $20(2 \%)$ & 1.6 & 0.112 \\
\hline & & Female & $49(4 \%)$ & & \\
\hline & Two root canals & Male & 32 (3.3\%) & 5.3 & $0.000^{*}$ \\
\hline & & Female & 102 (8.4\%) & & \\
\hline
\end{tabular}

†Statistical analysis not performed.

*Difference is statistically significant $(p<0.001)$.

In cases where each type of tooth was contralaterally present in the mouth, the overall bilateral symmetry for the number of roots or root canals ranged $96-100 \%$ or $90-95 \%$, respectively (Table 3). When the contralateral tooth was present and at least one of the teeth had two roots or two root canals, bilateral symmetry was present in $0 \%$ or $45.0 \%$ of cases for the central incisors, $0 \%$ or $29.0 \%$ for the lateral incisors, and $17.6 \%$ or $28.0 \%$ for the canines (Figure 3).

The effect of age was examined for the number of canals only. Statistically significant differences were found between patients over 56 years and patients in the other age groups, with a lower frequency of two root canals being detected among patients over 56 years ( $\mathrm{p} \leq 0.001$ by $\mathrm{z}$-test, Table 4 ).

\section{Discussion}

Among the tooth types, two roots or two root canals were most frequently seen in the mandibular canines or the mandibular incisors, respectively. When two roots and/or root canals were observed in a patient, the location was mostly unilateral. Presence of a second root canal was inversely related to age. Canine teeth with two root canals were more frequently found in females compared to males. 
Table 3. Cases in which the number of roots or root canals is bilaterally symmetric. Total number represents the number of cases in which the tooth is contralaterally present in the mouth.

\begin{tabular}{lccc}
\hline \multicolumn{1}{c}{ Teeth } & Bilaterally symmetric cases for root number & Bilaterally symmetric cases for root canal number & Total number \\
\hline Central incisor & $973(100 \%)$ & $923(94.8 \%)$ & 973 \\
Lateral incisor & $1008(99.8 \%)$ & $907(89.8 \%)$ & 1010 \\
Canine & $1019(95.5 \%)$ & $995(93.3 \%)$ & 1067 \\
\hline
\end{tabular}

Morphologies and root canal configurations of mandibular incisors and canines have been extensively studied by various techniques. ${ }^{6,10,11,15,17,18,19,20,21,22,23}$ The presence of two roots in a mandibular incisor is a rare finding. ${ }^{24}$ In this study, two roots were observed in the lateral incisors of two female patients. The presence of two-rooted mandibular canines in the current study (3.1\%) is in agreement with previous findings (prevalence range of $0.3-6.2 \%$ ). ${ }^{3,5}$

Compared to the prevalence of two roots, previous studies have found greater variations in the prevalence rates of two root canals in incisors (11-68\% $)^{4,10,18-23,25,26}$ and canines $(6-38 \%) \cdot{ }^{3,5,10,21,26}$ These variations may

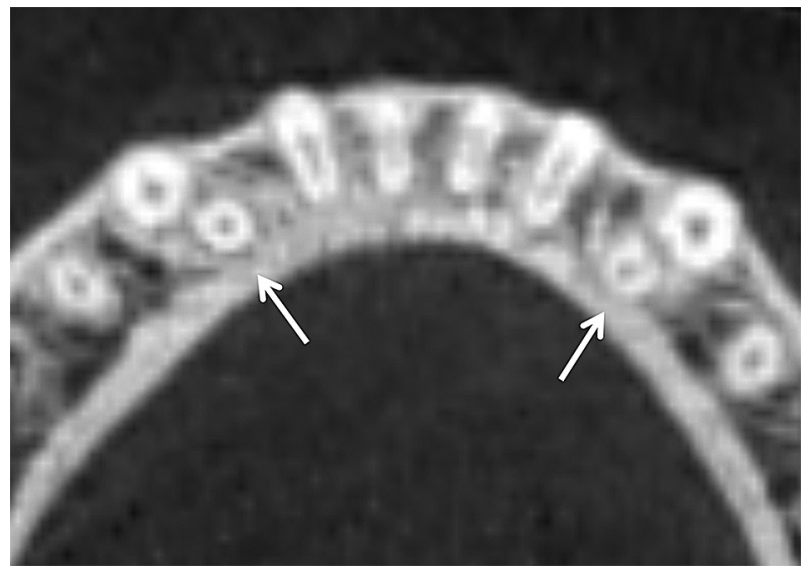

Figure 3. Axial section showing bilateral two-rooted canines (arrows).

Table 4. Number of teeth with two root canals and the sample size (all examined teeth) in different age categories, and statistical comparisons between categories.

\begin{tabular}{lc}
\hline Age category (years) & Proportion (\%) \\
\hline $10-35$ & $337 / 2537(13.3 \%)$ \\
$36-55$ & $336 / 2445(13.7 \%)$ \\
$56+$ & $123 / 1271(9.7 \%)$ \\
Total & $796 / 6253(12.7 \%)$ \\
\hline
\end{tabular}

Comparisons: $10-35$ years vs. 36-55 years, $\mathrm{z}$-value $=0.4, \mathrm{p}=0.68$; $36-55$ years vs. $56+$ years, $z$-value $=3.5, p<0.001 ; 10-35$ years vs. $56+$ years, $\mathrm{z}$-value $=3.2, \mathrm{p}=0.001$. be due to geographical differences or differences in detection techniques. The present study found results similar to previous studies for the incisors (14.9\% and $17.2 \%)$, whereas the finding for the canines $(6.1 \%)$ corresponded to the lower range of previous findings. Compared to other studies in Turkish populations, the findings of the current study for the prevalence rates of two root canals in incisors and canines are very similar to those of Karagöz-Küçükay ${ }^{25}$ (15\% for incisors), Caliskan et al. ${ }^{26}$ (16\% for incisors, $6 \%$ for canines), and Altunsoy et al. ${ }^{23}$ (17\% for incisors, $7 \%$ for canines). Prevalence rates reported by Sert and Bayirli $^{21}$ (68\% incisors, 38\% canines) differ from those of other Turkish population studies.

Anatomical symmetry in tooth properties is clinically important when treating contralateral teeth in the same patient. ${ }^{12}$ However, the literature contains little information regarding the symmetry of root canals in the mandibular anterior teeth. Compared to the available information, all of which comes from Chinese studies, ${ }^{11,15}$ the present study examined a different ethnic population and a greater number of teeth. In one of these Chinese studies, double root canal formation was predominantly bilateral in the mandibular incisors and unilateral in the canines. ${ }^{15}$ Although the rates of bilateral double root canal were relatively lower in the present study, the finding that the bilateral double root canal was seen more in the incisors is similar. In another study conducted on mandibular incisors, overall symmetry in the root canal numbers was found in $94-95 \%$ of the cases, ${ }^{11}$ compared to $90-95 \%$ in the current study (Table 3).

Bifurcations in teeth pose difficulties to clinicians during endodontic treatment. Negotiating and shaping the root canals may be difficult in two-rooted teeth when the bifurcation is apically located. The lingual canal may be particularly difficult to locate, and the clinician may need to modify the coronal access to facilitate its localization. In this case, an inability 
to instrument or obturate one of the root canals may jeopardize treatment success. Previous studies have found furcation points to be located mostly at the middle third, to a lesser extent at the apical third, and, least frequently, at the cervical third in canines. ${ }^{6,17}$ The results of the current study are in line with these findings. Previous studies also reported approximately equal root lengths for two-rooted canines. ${ }^{6,17}$ In the current study, the buccal roots were slightly longer than the lingual roots. Both roots were slightly longer in males than in females, albeit without statistical significance. The latter finding is consistent with the report of a greater mandibular symphysis height in males compared to females in a Turkish anthropometric study of young adults. ${ }^{27}$

Among the demographic variables, gender and age were partly associated with the presence of two root canals. Although the prevalence of two root canals in incisors was similar in males and females, double root canals in canines were seen significantly more often in females. This finding is quite similar to that of a previous Turkish study, ${ }^{21}$ although other studies have reported a statistically significant difference between genders for the incisors. ${ }^{11,23}$

Age displayed an inverse relationship with the frequency of two root canals, probably due to the deposition of secondary dentin in the root canal, which may ultimately result in obliteration of the root

\section{References}

1. Vertucci FJ, Haddix JE. Tooth morphology and access cavity preparation. In: Hargreaves KM, Cohen S, editors. Cohen's Pathways of the pulp. St. Louis( MO): Mosby Elsevier; 2011. p. 136-222.

2. Victorino FR, Bernardes RA, Baldi JV, Moraes IG, Bernardinelli $\mathrm{N}$, Garcia RB, et al. Bilateral mandibular canines with two roots and two separate canals: case report. Braz Dent J. 2009;20(1):84-6.

3. Aminsobhani M, Sadegh M, Meraji N, Razmi H, Kharazifard MJ. Evaluation of the root and canal morphology of mandibular permanent anterior teeth in an Iranian population by cone-beam computed tomography. J Dent (Tehran). 2013 May;10(4):358-66.

4. Liu J, Luo J, Dou L, Yang D. CBCT study of root and canal morphology of permanent mandibular incisors in a Chinese population. Acta Odontol Scand. 2014 Jan;72(1):26-30. canal space. In support of this possibility, a previous study of the maxillary incisors found that the root canal space decreases with increasing age, ${ }^{28}$ and that the middle mesial root canal in mandibular molars is less frequently seen in older patients. ${ }^{29} \mathrm{~A}$ literature search revealed only two studies ${ }^{11,15}$ (reference no. 15; article written in a non-English language) that have investigated the relationship between age and the number of root canals in the mandibular anterior teeth. In one of these studies, no significant difference was found between the frequencies of two root canals in the teeth of patients in various age groups. ${ }^{11}$

\section{Conclusion}

Most of the mandibular anterior teeth examined in this study had a single root and canal. Prevalence of two roots or two root canals ranged $0-3 \%$ or $6-17 \%$, respectively. Males and females had statistically similar numbers of roots and root canals, but females more often had canine teeth with two root canals. An inverse relationship was found between age and the presence of a second root canal. Bilateral symmetry for the presence of two roots or two root canals for individual teeth ranged $0-18 \%$ or $28-45 \%$, respectively. Clinically, these findings are important in terms of looking for a second canal in the mandibular anterior teeth, particularly when endodontic treatment is to be performed in the contralateral teeth of a patient.

5. Pécora JD, Sousa Neto MD, Saquy PC. Internal anatomy, direction and number of roots and size of human mandibular canines. Braz Dent J. 1993;4(1):53-7.

6. Sharma R, Pécora JD, Lumley PJ, Walmsley AD. The external and internal anatomy of human mandibular canine teeth with two roots. Endod Dent Traumatol. 1998;Apr 14(2):88-92.

7. Schwarze T, Baethge C, Stecher T, Geurtsen W. Identification of second canals in the mesiobuccal root of maxillary first and second molars using magnifying loupes or an operating microscope. Aust Endod J. 2002;Aug 28(2):57-60.

8. Omer OE, Al Shalabi RM, Jennings M, Glennon J, Claffey NM. A comparison between clearing and radiographic techniques in the study of the root-canal anatomy of maxillary first and second molars. Int Endod J. 2004 May;37(5):291-6. 
9. Yoshioka T, Kikuchi I, Fukumoto Y, Kobayashi C, Suda H. Detection of the second mesiobuccal canal in mesiobuccal roots of maxillary molar teeth ex vivo. Int Endod J. 2005;Feb 38(2):124-8.

10. Rahimi S, Milani AS, Shahi S, Sergiz Y, Nezafati S, Lotfi M. Prevalence of two root canals in human mandibular anterior teeth in an Iranian population. Indian J Dent Res. 2013 Mar-Apr;24(2):234-6.

11. Lin Z, Hu Q, Wang T, Ge J, Liu S, Zhu M, et al. Use of CBCT to investigate the root canal morphology of mandibular incisors. Surg Radiol Anat. 2014 Nov;36(9):877-82.

12. Plotino G, Tocci L, Grande NM, Testarelli L, Messineo D, Ciotti M, et al. Symmetry of root and root canal morphology of maxillary and mandibular molars in a white population: A cone-beam computed tomography study in vivo. J Endod. 2013 Dec;39(12):1545-8.

13. Yang R, Yang C, Liu Y, Hu Y, Zou J. Evaluate root and canal morphology of primary mandibular second molars in Chinese individuals by using cone-beam computed tomography. J Formos Med Assoc. 2013 Jul;112(7):390-5.

14. Huang YD, Wu J, Sheu RJ, Chen MH, Chien DL, Huang $\mathrm{YT}$, et al. Evaluation of the root and root canal systems of mandibular first premolars in northern Taiwanese patients using cone-beam computed tomography. J Formos Med Assoc. 2014 Aug 28. pii: S0929-6646(14)00179-X. doi: 10.1016/j.jfma.2014.05.008.

15. Zhao Y, Dong YT, Wang XY, Wang ZH, Li G, Liu MQ, et al. Cone-beam computed tomography analysis of root canal configuration of 4674 mandibular anterior teeth. Beijing Da Xue Xue Bao. 2014 Feb;46(1):95-9.

16. Vertucci FJ. Root canal anatomy of the human permanent teeth. Oral Surg Oral Med Oral Pathol. 1984 Nov;58(5):589-99.

17. Versiani MA, Pecora JD, Sousa-Neto MD. The anatomy of two-rooted mandibular canines determined using micro-computed tomography. Int Endod J 2011 Jul;44(7): 682-7.
18. Green D. A stereomicroscopic study of the root apices of 400 maxillary and mandibular anterior teeth. Oral Surg Oral Med Oral Pathol. 1956 Nov;9(11): 1224-8.

19. Vertucci FJ. Root canal morphology of the mandibular anterior teeth. J Am Dent Assoc. 1974 Aug;89(2): 369-71.

20. Kartal N, Yanikoglu FC. Root canal morphology of mandibular incisors. J Endod. 1992 Nov;18(11):562-4.

21. Sert S, Bayirli GS. Evaluation of the root canal configurations of the mandibular and maxillary permanent teeth by gender in the Turkish population. J Endod. 2004 Jun;30(6):391-8.

22. Perlea P, Nistor CC, Toma C, Dimitriu B. Endodontic configuration of the lower incisors in a Romanian population: a radiological study. Rom J Morphol Embryol. 2013;54(3 Suppl):775-8.

23. Altunsoy M, Ok E, Nur BG, Akkemik O, Ok E, Evcil MS. A cone-beam computed tomography study of the root canal morphology of anterior teeth in a Turkish population. Eur J Dent. 2014 Jul;8(3):302-6.

24. Loushine RJ, Jurcak JJ, Jeffalone DM. A two-rooted mandibular incisor. J Endod. 1993 May;19(5):250-1.

25. Karagöz-Küçükay I. Root canal ramifications in mandibular incisors and efficacy of low-temperature injection thermoplasticized gutta-percha filling. J Endod. 1994 May;20(5):236-40.

26. Caliskan MK, Pehlivan Y, Sepetçioğlu F, Turkun M, Tuncer SS. Root canal morphology of human permanent teeth in a Turkish population. J Endod. 1995 Apr;21(4):200-4.

27. Uysal T, Yagci A, Ozer T, Veli I, Ozturk A. Mandibular anterior bony support and incisor crowding: Is there a relationship? Am J Orthod Dentofacial Orthop. 2012 Nov;142(5):645-53.

28. Kaya S, Adiguzel O, Yavuz I, Tumen EC, Akkus Z. Cone-beam dental computerized tomography for evaluating changes of aging in the dimensions central superior incisor root canals. Med Oral Patol Oral Cir Bucal. 2011 May;16(3):e463-6.

29. Nosrat A, Deschenes RJ, Tordik PA, Hicks ML, Fouad AF. Middle mesial canals in mandibular molars: incidence and related factors. J Endod. 2015 Jan;41(1):28-32. 